\title{
Tracking electricity generation attributes in Europe
}

\author{
W. Lise ${ }^{\mathrm{a}, \mathrm{c}, *}$, C. Timpe ${ }^{\mathrm{b}}$, J.C. Jansen ${ }^{\mathrm{a}}$, M. ten Donkelaar ${ }^{\mathrm{a}}$ \\ ${ }^{\text {a }}$ Energy Markets and International Environmental Policy Group, ECN Policy Studies, Energy Research Centre of the Netherlands, Amsterdam, \\ The Netherlands \\ ${ }^{\mathrm{b}}$ Energy and Climate Division, Öko-Institut e.V., Institute for Applied Ecology, Freiburg, Germany \\ ${ }^{\mathrm{C} I B S}$ Research \& Consultancy, Agahamami Cadessi 1/6, Aga Han, Cihangir, 34433 Beyoglu, Istanbul, Turkey
}

Received 24 July 2006; accepted 16 July 2007

Available online 24 August 2007

\begin{abstract}
Tracking electricity generation attributes can yield detailed information on the used electricity generating technologies, such as per unit fuel consumption and emissions to the environment. The policy context matters for defining the attributes to be tracked. Evolving experience with tracking greatly facilitates the implementation of reliable tracking systems. Some EU Member States have already gained experience with electronically tracked generation attributes for the purpose of disclosing the generation mix to the consumer. Another major application is the use for facilitation of support systems for renewable electricity. There are factors rendering the introduction of tracking generation attributes in Europe no easy task. The main problem is the widely varying initiatives among EU Member States to implement legislation on Guarantees of Origin and disclosure, as this greatly complicates trans-border transfers of generation attributes. The amount of electricity traded makes it difficult to link generation to consumption under "contract-tied tracking", while this is of no concern under "de-linked tracking". The key towards overcoming the aforementioned barriers is harmonisation of schemes for tracking generation attributes.
\end{abstract}

(C) 2007 Elsevier Ltd. All rights reserved.

Keywords: Tracking electricity generation attributes; European electricity market; Guarantees of Origin

\section{Introduction}

Once a generation device has fed its electricity into the public grid, the flow of electrons to specific consumers cannot be traced, because electricity in the grid is physically homogeneous and there is no way of distinguishing "brown", "green", "grey" or "yellow" electrons. Hence, to inform the consumer with the generation attributes, a tracking system is required which matches electricity consumed to electricity generated in an unequivocal way according to agreed upon pre-set conventions. The focus of this paper is on tracking electricity generation attributes in Europe, also in relation with market and policy conditions, and subsequently derives recommendations for the design of tracking systems.

\footnotetext{
*Corresponding author. IBS Research \& Consultancy, Agahamami Cadessi 1/6, Aga Han, Cihangir, 34433 Beyoglu, Istanbul, Turkey. Tel.: + 902122522460 ; fax: + 902122522430 .

E-mail address: wietze.lise@ibsresearch.com (W. Lise).
}

Tracking is a procedure to allocate electricity generation attributes to individual consumers or groups of consumers (such as all customers of a supply company or all customers of a specific electricity product). Generation attributes mean any piece of information about the process of electricity generation, which might be of relevance for energy consumers, other market actors, governments or regulators. Such attributes might generally include information about the energy source and the technology used for electricity generation and the emissions and nuclear waste associated with the generation process, but could also include more "indirect" attributes such as details on financial support received and whether the employees of power plants are unionised or not. ${ }^{1}$

The liberalisation of the European electricity market has introduced competition among electricity companies. Simultaneously, new opportunities have arisen where the

\footnotetext{
${ }^{1}$ This has been an issue of interest for consumers in some of the US states.
} 
market can start playing a role in reaching a higher share of sustainable generation and marketing of electricity. To stimulate sustainable generation, various European directives, national policies and initiatives have been introduced. One of the most important regulations in this regard is the Renewables Directive (2001/77/EC), which aims at a share of renewables in electricity generation (RES-E) of $21 \%$ by 2010 for EU25 (SEC, 2004). In addition, the Cogeneration Directive (2004/8/EC) aims at encouraging the simultaneous generation of heat and power. These directives are not mutually exclusive, as there is also generation with biomass, which can be used for high-efficiency cogeneration for heat and power (HE-CHP).

Article 5 of the Renewables Directive introduced the concept of Guarantees of Origin (GO) for RES-E. As of 27 October 2003, EU15 Member States were required to have legislation in place to establish a system that will enable renewable energy generators to obtain GO for the electricity produced from their plants. This legislation means that generators will be able to request a GO as evidence that they have generated a certain amount of electricity from eligible renewable sources. The system is purely voluntary for the generators, with individual generators being left to decide if they wish to make such a request. Also the Cogeneration Directive mandates the introduction of national GO systems for electricity originating from HE-CHP plants "for the transparency of consumer's choice".

It is difficult to identify technologies that are clean and green and to give them just the right push for just the right period of time to make them competitive with conventional technologies and just attractive enough to be invested in. Hence, there is a need for timing the incentive to such an extent that there is no oversubsidising, but also that the investment remains sufficiently attractive to be undertaken. EU Member States have put in place three main types of support policies to increase the share of RES-E and HECHP, i.e. feed-in tariffs (including premiums on top of the electricity market price), quota obligations ${ }^{2}$ and fiscal measures as well as a number of other targeted measures.

Past and ongoing experiences with regulatory and policy conditions can be useful for the design of a tracking system. However, the effectiveness of different tracking mechanisms depends on the current electricity market conditions, which vary considerably among EU Member States. Market conditions can have an impact on the design of a tracking mechanism, because tracking must be able to cope with the current differences in the regional electricity markets (Boardman et al., 2003, p. 40). Moreover, the tracking system must be able to deal with changes that are taking place in the physical networks, market structures and generation technologies.

The generation and consumption of electricity is linked by commercial contracts, independent of physical electron flows. A tracking system can either run in parallel to

\footnotetext{
${ }^{2}$ Also often referred to as renewable portfolio standards (RPSs).
}

electricity contract links tying the attributes to electricity contracts ("contract-tied tracking"), or establish an independent accounting mechanism for the transfer of generation attributes that eventually assigns these characteristics to the electricity consumed by final customers ("de-linked tracking"). These are the major possibilities for so-called explicit tracking. The current practice is, however, mainly an implicit tracking mechanism using various statistics, which are available to the supplier.

The outline of this paper is as follows. Section 2 deals with the main driver for tracking generation attributes. The role of tracking in policies for stimulating renewable electricity generation is studied in Section 3. The link between tracking and the current dynamics in the electricity market is pointed out in Section 4. Possibilities of explicit tracking are described in Section 5. Section 6 provides an overview of possible stakeholder positions towards the introduction of tracking. The final section provides conclusions, areas for further research and lessons learnt.

\section{Drivers for tracking generation attributes}

There are three major uses for tracking generation attributes $^{3}$ :

(1) Proof of generation for a specific support scheme, such as RES-E or HE-CHP, like feed-in tariffs and quota obligation schemes, as well as some fiscal measures.

(2) Proof of generation in a reporting scheme, in particular disclosure of generation attributes to the consumer (Article 3 (6) of Electricity Directive 2003/54/EC), but this may also include green quality labels and Guarantees of Origin for RES-E and HE-CHP (Article 5 of the Renewables Directive and Article 5 of the Cogeneration Directive).

(3) Accounting for the national indicative targets for RESE as set out in Article 3 of the Renewables Directive.

These uses may also be interpreted wider, to assist more accurate accounting for general energy sector transparency. These three (or more) uses can be positive drivers for the introduction of an accurate tracking mechanism for electricity generation attributes.

This paper intends not to predetermine the design of support mechanisms used by EU Member States through the tracking mechanism. Moreover, tracking should be policy neutral, where the tracking scheme is designed in a way that different support schemes can be facilitated. However, the introduction of a tracking scheme might require some corrections to support schemes, mainly to avoid multiple counting of attributes. ${ }^{4}$

\footnotetext{
${ }^{3}$ Here we have mentioned three purposes, which are the main ones, but there are also other more indirect purposes. See, for instance, Jansen (2003, 2005a, b), Kristiansen et al. (2005), Van der Linden et al. (2004) and Vrolijk et al. (2004).

${ }^{4}$ Multiple counting of attributes is defined as a situation where the attributes of the same instance of generated electricity $(1 \mathrm{MWh})$ is claimed
} 
Disclosure of generation attributes to the consumer can facilitate consumer choice. Hence, an improved transparency of the market, irrespective of the contents of disclosure, is a non-monetary benefit on its own. For example, it might enable "green" niche suppliers to enter the increasingly concentrated European electricity market and may prompt European generators to deploy more green technologies within their generating portfolios. More generally, any kind of electricity generation could benefit from disclosure, depending on consumer preferences, whereas traditional generation technologies like coal, nuclear and gas need to prove themselves to the consumer, possibly leading to major shifts in new investments in generation technologies. Moreover, it may provide market participants with relevant information and it might also increase the confidence of a consumer into the "green" credentials of the supplier.

The opening up of the electricity market in the European Union will gradually give all consumers a choice of supplier. This choice can be based on price, on quality and reliability of service, but can also relate to the generation characteristics of the electricity supplied. The Electricity Directive, therefore, introduces the obligation on suppliers to specify the fuel mix and its related environmental impact of the electricity they sell to final consumers. ${ }^{5}$

This new obligation on suppliers, i.e. to specify the fuel mix and its related environmental impact, is the requirement of the so-called "disclosure of electricity generation attributes". To achieve this, there is a need for a wellfunctioning tracking system.

A fundamental prerequisite for disclosure of generation attributes is the need for unambiguous links between power plants and electricity sold to final consumers. These links are used to transfer information about power generation attributes to electricity suppliers and finally to consumers. In an ex-post scheme, such as the EU minimum disclosure requirement, the tracking system generates the information provided by the tracking system that will be accumulated to total figures over a previous period (usually a calendar year) ${ }^{6}$

The GO provision in the Renewables Directive does not focus on how a GO system should be designed in detail. Also, the relation of the GO to disclosure as defined by the Electricity Directive is not specified in the two directives. It

\section{(footnote continued)}

more than once for the same purpose or for conflicting purposes. There can be various types of multiple counting, namely multiple uses for the same purpose, or (single or multiple) use of attributes for a specific amount of fictive generation for single or multiple purposes (Uyterlinde et al., 2004).

${ }^{5}$ Note of DG Energy \& Transport on Directives 2003/54 and 2003/55 on the internal market in electricity and natural gas - Labelling provision in Directive 2003/54/EC.

${ }^{6}$ Lise et al. (2006a, b) provide detailed information on the level of implementation of disclosure in 33 countries, including the US and Australia. is therefore left to Member States whether or not GO are part of the tracking scheme supporting disclosure.

Moreover, it is not predetermined whether GO should be transferred together with the underlying contractual electricity flows or not. Two major views exist, which correspond to the two options for explicit tracking of generation attributes as mentioned in the previous section:

- The linked approach, where GO are transferred in parallel with the contractual electricity flows.

- The de-linked approach, unbundling the sale of electricity from the transfer of the GO referring to the production concerned.

It is also helpful to highlight the limitation of these two views in relation to GO. On the one hand, the linked approach can be difficult, e.g. due to the fact that contracted and actually delivered electricity usually differ. On the other hand, the de-linked approach loses the direct link to electricity and a second market for certificates is needed.

Accurate accounting for the national indicative targets for RES-E is useful and needed for EU Member States. However, since these targets are indicative only and there are no financial sanctions for non-compliance, accurate monitoring may be considered by some as less important.

In addition to these three drivers, it is also interesting to point out their interaction with the $\mathrm{EU} \mathrm{CO}_{2}$ Emission Trading System (ETS). ${ }^{7}$ The ETS is an allowance scheme, which places a cap on total $\mathrm{CO}_{2}$ emissions from certain types of plants in the EU. The emitters, i.e. the operators of fossil-fuel power plants as well as certain other devices, which are subject to the ETS scheme, have to redeem a sufficient number of emission allowances to cover the actual emissions from their plants. In the course of disclosure of electricity generation attributes, the attribute of actual $\mathrm{CO}_{2}$ emissions of electricity generation has to be tracked from the producer to the consumer in some way. The monitoring data from the EU ETS could be used by the electricity disclosure scheme.

\section{Role of tracking in policies to stimulate "greener" electricity generation}

\subsection{Feed-in tariffs}

Feed-in tariffs are granted to eligible "green" generators feeding their generation into the national grid, where the EU Member States are running the feed-in tariffs schemes. Generally, these preferential tariffs are passed through to end users (e.g. via the TSO) as mandated by state legislation to increase the share of RES-E in power

\footnotetext{
${ }^{7}$ See also Van der Linden et al. (2004) for the interactions of EU-ETS with GO for renewables.
} 
generation. ${ }^{8}$ Hence, this instrument usually concerns an obligation for a system operator to purchase eligible electricity generation and to pay a defined minimum price.

The price guarantee is introduced to make RES-E technologies competitive in the market and to make investments in RES-E sufficiently attractive. Usually, the tariffs for eligible technologies (typically most RES-E technologies except large hydro power) are differentiated for the individual technologies and are reduced over time, in order to stimulate and reflect technological development, which leads to reductions in generation cost and to avoid oversubsidisation. Transparent tracking could make sure that feed-in tariffs are provided only once per eligible MWh of electricity, avoiding multiple counting.

Currently, in all EU Member States with a feed-in tariff system as the main support mechanism, no (full) integration of GO into administering such support systems takes place. In the Netherlands, GO play a certain role in administrating the feed-in tariff support system. However, also in this country, generators operating a plant that is eligible for a feed-in premium do not need to redeem (surrender) GO for receiving premium income. Also, in EU Member States with feed-in tariffs as the main support mechanism, GO can be obtained for a very small trading margin on top of administration costs for disclosure or other purposes in the order of $€ 0.2-0.5$ per GO of $1 \mathrm{MWh}$, including administration costs charged for GO tracking.

\subsection{Quota obligations}

An EU Member State government or regulator may oblige market players to generate (or to purchase) a certain amount of electricity from pre-defined sources or technologies. ${ }^{9}$ As an alternative to this "physical" quota, the obligation can also be met financially, i.e. to provide support a certain volume of eligible generation. Such a quota obligation is usually put in place to support renewable energy sources, but in principle it may also incorporate HE-CHP. The obligation is normally allocated to supply companies and is defined as a percentage of the total electricity demand.

To administer the quota obligation scheme, also referred to as a renewables portfolio standard, a transparent tracking mechanism is essential. Tradable renewable electricity certificates (TRECs) ${ }^{10}$ are issued to producers for units of electricity generated from qualifying sources, and redeemed by the obliged parties to meet their quota obligation. Penalties are in place to encourage compliance with the targets. Currently, in all EU Member States, with

\footnotetext{
${ }^{8}$ In several member states, certain energy-intensive manufacturing establishments are exempted or granted discounts on the preferential tariffs to be paid.

${ }^{9}$ According to Table 1 there are five EU member states where this is actually taking place.

${ }^{10}$ Quite a few other terms are used with often slightly different connotations, for example, notably in the United States, renewable energy certificates (RECs).
}

a quota-based system as main support mechanism, a TREC system exists. The TRECs has a value in a wide range of $€ 15-100 / \mathrm{MWh}$, depending among others on national policy ambitions.

\subsection{Fiscal measures}

Various fiscal measures may be introduced to stimulate renewable generation. These are generally not in the form of actual subsidies, but in the form of tax rebates and tax exemptions. This tax instrument is very flexible as it can be targeted at producers, suppliers and consumers. Fiscal measures may be used to stimulate RES-E, HE-CHP and energy efficiency and discourage undesired investments. The flexibility can also be a threat, as it is very difficult to avoid perverse subsidies/tax rebates where technologies are subsidised, which could survive in the market without subsidy. In the case of fiscal measures, the generator can usually sell its product on the electricity market with no limitations, i.e. the support mechanism is separated from the disclosure attributes. Tracking could assist in avoiding multiple counting by making tax rebates transparent.

Table 1 shows that in most EU Member States feed-in tariffs are used to stimulate the share of RES-E in the electricity generation mix. Quota obligation schemes have been implemented in Belgium, Italy, Poland, Sweden and UK. The presence of natural resources, whether electricity can be generated from hydro or wind power, varies considerably among EU Member States. The ambition to increase the share of RES-E also varies. Denmark is most ambitious with an increase in RES-E share of more than $20 \%$, followed by Slovakia, Greece and Sweden with an increase in RES-E share of more than $10 \%$. Portugal is least ambitious with an increase of $0.5 \%$, followed by Luxemburg, Lithuania and Slovenia with an increase of less than $4 \%$.

\section{The link between electricity market conditions and tracking}

\subsection{Level of market opening}

In a fully opened market a customer can switch supplier, while this is not possible in a closed market. The level of market opening varies considerably among the EU Member States, ranging from full opening in the Austrian, British, Dutch, German, Iberian and Nordic market to a partial opening in the market of other EU Member States. The level of market opening in the new EU Member States and EU Accession Countries is relatively diverse, but full market opening has not yet been reached in most of these countries.

In relation to market opening, it is of interest to consider the amount of customer switching or contract renegotiation by consumers that occurred after opening the market. In a fully opened market, the amount of switching/ renegotiation is generally higher. A higher level of market 
Table 1

Regulatory, policy and electricity market conditions in the EU25

\begin{tabular}{|c|c|c|c|c|c|c|c|}
\hline Country & $\begin{array}{l}\text { Feed-in tariffs } \\
\text { RES-E }\end{array}$ & $\begin{array}{l}\text { Obligation } \\
\text { scheme RES-E }\end{array}$ & $\begin{array}{l}\text { RES-E } 1997 \\
\text { level }(\%)\end{array}$ & $\begin{array}{l}\text { RES-E } 2010 \\
\text { target }(\%)\end{array}$ & $\begin{array}{l}\text { Market } \\
\text { opening }^{\mathrm{a}}(\%)\end{array}$ & $\begin{array}{l}\text { Market } \\
\text { concentration }\end{array}$ & $\begin{array}{l}\text { Coordinated } \\
\text { operation } \\
\text { through }\end{array}$ \\
\hline Austria & Yes & & 70.0 & 78.1 & 100 & High & UCTE \\
\hline Belgium & & Yes & 1.1 & 6.0 & 90 & Medium & UCTE \\
\hline Cyprus & Yes & & 0.1 & 6.0 & 35 & High & Cyprus \\
\hline Czech Republic & Yes & & 3.8 & 8.0 & 47 & Medium & UCTE \\
\hline Denmark & Yes & & 8.7 & 29.0 & 100 & Low & UCTE/Nordel \\
\hline Estonia & Yes & & 0.2 & 5.1 & 10 & High & Russia \\
\hline Finland & Yes & & 24.7 & 31.5 & 100 & Low & Nordel \\
\hline France & Yes & & 15.0 & 21.0 & 70 & High & UCTE \\
\hline Germany & Yes & & 4.5 & 12.5 & 100 & Medium & UCTE \\
\hline Greece & Yes & & 8.6 & 20.1 & 62 & High & UCTE \\
\hline Hungary & Yes & & 0.7 & 3.6 & 67 & Medium & UCTE \\
\hline Ireland & Yes & & 3.6 & 13.2 & 56 & High & Ireland \\
\hline Italy & Yes & Yes & 16.0 & 25.0 & 79 & Medium & UCTE \\
\hline Latvia & Yes & & 42.4 & 49.3 & 76 & High & Russia \\
\hline Lithuania & Yes & & 3.3 & 7.0 & 70 & High & Russia \\
\hline Luxemburg & Yes & & 2.1 & 5.7 & 57 & Medium & UCTE \\
\hline Malta & Yes & & 0.0 & 5.0 & 0 & High & Malta \\
\hline Netherlands & Yes & & 3.5 & 9.0 & 100 & Medium & UCTE \\
\hline Poland & & Yes & 1.6 & 7.5 & 52 & Low & UCTE \\
\hline Portugal & Yes & & 38.5 & 39.0 & 100 & Medium & UCTE \\
\hline Slovakia & Yes & & 17.9 & 31.0 & 66 & Medium & UCTE \\
\hline Slovenia & Yes & & 29.9 & 33.6 & 75 & Medium & UCTE \\
\hline Spain & Yes & & 19.9 & 29.4 & 100 & Medium & UCTE \\
\hline Sweden & & Yes & 49.1 & 60.0 & 100 & Low & Nordel \\
\hline UK & & Yes & 1.7 & 10.0 & 100 & Low & UK \\
\hline
\end{tabular}

Source: EU (2004), SEC (2004).

${ }^{\mathrm{a}}$ As of January 1, 2004 (EU, 2004).

opening in EU Member States largely enhances the usefulness of tracking and the information on generation attributes for consumers. Currently major efforts are underway to harmonise the level of market opening in the EU.

\subsection{Competition}

There are more benefits from tracking under a liquid and competitive market, where consumers presumably can switch more easily among producers and where cheaper or cleaner electricity product offerings are available. However, opening up of the market has, for instance, led to mergers and acquisitions to such an extent that it negatively affects competition. The German and Dutch wholesale markets, for example, have become oligopolistic in nature, possibly reducing the benefits of competition in a wave of mergers immediately after opening the wholesale market. Concentration of market power can potentially lead to market distortions and imperfections for which the consumers have to pay a higher price. Hence, market opening does not automatically lead to more competitiveness and market liquidity.

Table 1 shows that most EU Member States have a moderate market concentration, while high market concentrations are found in Cyprus, Estonia, Greece, France,
Ireland, Latvia, Lithuania and Malta; low market concentrations are found in the Nordic market, Poland and the UK. Most EU Member States are connected to the network of the UCTE. Table 1 also shows that electricity markets are not harmonised or liberalised to the same degree across Europe. With the exception of the Scandinavian region, most electricity markets operate almost exclusively on a national basis. However, in mainland Europe, the continued expansion and strengthening of the UCTE system and the Florence process are working towards a greater integration of the wholesale markets. So far, regional harmonisation and integration of national electricity markets is taking place. For example, the markets of Spain and Portugal are merging into a single Iberian market and the national regulators of France, Belgium and the Netherlands have prepared a roadmap for the integration of the wholesale electricity markets (CRE et al., 2005).

Competition at the wholesale level is an indispensable element of a functioning electricity market. Moreover, more competition also enhances the ability to switch for the consumer. As already stated, differentiation of electricity products by way of generation attributes tracking, and enables green electricity providers to enter the market. This, in turn, may have a (modest) positive impact on market efficiency. 
Table 2

Volume traded in the national power exchanges and total consumption

\begin{tabular}{|c|c|c|c|c|}
\hline Country & Total consumption (TWh) & Volume traded (TWh) & Percentage $(\%)$ & Exchange \\
\hline Austria & 54 & 1 & 1.9 & EXAA \\
\hline France & 393 & 14 & 3.6 & Powernext \\
\hline Germany & 499 & 59 & 11.8 & EEX \\
\hline Italy & 282 & 15 & 5.3 & GME \\
\hline Lithuania & 8 & 1.5 & 18.8 & LPC \\
\hline Netherlands & 100 & 15 & 15.0 & APX \\
\hline Denmark, Finland, Norway, Sweden & 391 & 166 & 42.5 & Nordpool \\
\hline Poland & 103 & 1 & 1.0 & Gielda \\
\hline Slovenia & 12 & 0.4 & 3.3 & E-borzen \\
\hline Spain & 241 & 203 & 84.2 & OMEL \\
\hline UK & 333 & 35 & 10.5 & NETA, UKPX \\
\hline
\end{tabular}

Source: EU (2004, p. 18), EU (2005), OMEL (2005).

To sum up, aiming at a wider consumer choice increases the potential for trading, including cross-border cooperation and can improve competitiveness in the market. Tracking can play a facilitating role for achieving this.

\subsection{Domestic and cross-border trade}

A fundamental feature of liberalised electricity markets is that large shares of the generated energy are traded between market participants. Sometimes, in the case of forwards and futures, the electricity is traded several times before it is produced and consumed. There are several patterns of energy trading, including in-house deals, longterm bilateral contracts, over-the-counter (OTC) transactions and power exchanges. In addition to domestic trades, large volumes of electricity are traded across borders in Europe every day. Any system designed to track attributes therefore has to be able to take into account trading activity including such cross-border links.

Table 2 shows that trading over central exchanges took place in 13 EU Member States in 2003, whereas there were no exchanges in the remaining EU Member States. Most trade takes place on the OMEL in Spain (representing $84 \%$ of all generation/supply; this is because of the mandatory single-buyer system), followed by the Nordpool in the Nordic countries $(42 \%$ of generation/supply, which is currently the most advanced spot market). Also, substantial shares in total volume are traded in the German, Dutch, Lithuanian and UK power exchanges. These traded electricity volumes are transferred on an anonymous basis without direct relations between individual sellers and buyers. Therefore, it is impossible to track the original generation mix based on electricity traded on spot markets. However, trades on power exchanges can either be tracked by using GOs or, alternatively, average attributes of all electricity sold into the exchange over certain periods of time could be determined (Boardman et al., 2003).

The electricity grids of mainland Europe are interconnected through the UCTE network, and international exchanges have taken place through this channel for decades. Synchronous operation with neighbouring net- works with, for instance, the UK and the NORDEL system is also aimed at, but not yet achieved. Moreover, the interconnected area is increasing even further as a result of the economic and political transition of central and eastern European countries. Furthermore, interconnection capacity within the EU and to other regions outside the EU is increasing, ${ }^{11}$ and cross-border transfers are increasing rapidly with an increasing level of competition. Also, the liberalisation of the electricity markets has resulted in a few large multinational electricity companies, optimising their portfolio across Europe using the UCTE interconnection capacity.

The increasing volume of trade in the European electricity market necessitates the implementation of a reliable tracking system that can cope with cross-border trade and transfers. Moreover, cross-border trade in attributes of electricity production is already taking place on a large scale. The most active market for green electricity has been in the Netherlands with some 2.5 million households, as compared to 4 million households Europe-wide (www.greenprice.com, July 2004 estimate). Much of this demand has been met from foreign green electricity sources. Figures presented by the Association of Issuing Bodies (AIB), which operates the RECS certificate schemes, show cross-border transactions of certificates representing some $48 \mathrm{TWh}$ in 2005 alone (AIB, 2006).

\section{Explicit tracking of generation attributes}

\subsection{Contract-tied tracking}

Contract-tied tracking is defined as assigning the generation attributes of specific power plants to specific suppliers and final consumers in parallel with contractual arrangements in the wholesale electricity market.

In some instances, generation and supply is undertaken by the same company, namely a vertically integrated electricity company, and for those companies it is possible

\footnotetext{
${ }^{11}$ For instance, the EU has a target for transmission capacity of at least $10 \%$ of generation capacity for each member state (EU, 2001).
} 
that supplies can be obtained from their own generation capacity and are not traded externally. However, while many vertically integrated electricity companies still exist across Europe, generation and supply need to be unbundled from network operations based on EU and EU Member State legislation. In addition to this, utilities often use external trade for their portfolio management.

Yet, the consideration of contracts is complex. In addition to the power exchange, there are different types of contracts as already pointed out in Section 4.3. Boardman et al. (2003) show that forward contracts do not create any real problems with regard to contract-tied tracking, where the contracted amount has to be matched by a future physical flow of electricity.

An additional complication is that not all electricity delivered is based on bilateral contracts. In the Nordic market about $42 \%$ of the electricity is traded through the Nordpool spot market. A similar system may also emerge throughout the UCTE area.

Also, there is always a need for backup capacity and other system services to balance the grid in real time for variations in demand and supply, which are typically not included in bilateral contracts between generators and suppliers, but is rather contracted by the TSO and/or DSO (SKM, 2002). In a contract-tied tracking system, these would either have to be ignored, or allocated to consumers, e.g. on a pro rata basis.

Hence, contract-tied tracking could only work for that part of the market where sales are organised via unambiguous contracts, for various reasons including those above. Possibly the strongest argument against contract-tied tracking is that there are strong concerns about liquidity in the physical electricity market, as electricity generation attributes will differentiate the commodity and thus segment the market. Liquidity of the market is needed for a smooth negotiation of contracts. Without market liquidity, adequate price formation-a fundamental feature of any well-functioning market-is lacking.

\subsection{De-linked tracking}

Based on experiences already gained, a tracking system could be designed where GOs are assigned to each generated MWh of electricity for each fuel or technology. Indeed GOs representing proof of generation already exist in all EU Member States, but only for RES-E (and soon for HE-CHP). A number of EU Member States also have certificates in the form of TRECs, mainly for the purpose of quota obligation systems. The AIB, a European organisation aiming at becoming the leading enabler of international energy certificate schemes, is in the course

of implementing a full certificate system for any kind of electricity generation. Such certificates could be used for accounting in the electricity disclosure statement.
De-linked tracking can overcome many of the obstacles, which have been identified in a contract-tied system, because attributes can be transferred independently from electricity trading arrangements. However, the geographical borders of such tracking systems must be defined clearly.

Also, there is little direct experience with such an allencompassing tracking system, which would cover the whole electricity market. In this respect, it is noteworthy that the Austrian disclosure of generation attributes system is now to a major extent based on a broad-based system of GOs that are issued, transferred and redeemed electronically in a central registry. ${ }^{12}$ Further experience will accumulate over time, which may provide further insights into the merits of comprehensive tracking systems.

Despite relatively little experience, de-linked tracking seems to be the most precise and transparent way to track generation attributes in the electricity market. Moreover, it is important to set up a system that rules out undesired and unintended multiple counting. This does not include intended multiple counting, where, for instance, for each MWh both a GO for disclosure and a TREC for support is granted. From a legal perspective, this is not incompatible with the Renewables Directive. Yet, at least, it needs to be pointed out in advance to make it transparent. To achieve this, a system or register is needed to assign GOs to each generated $\mathrm{MWh}$ and redeem GOs for each consumed MWh (for a particular technology).

It should be added that the existing GO systems across Europe already cover a significant share of RES-E and HECHP plants, which will increase further when all new EU Member States have implemented the Renewables Directive and all EU Member States have fully implemented the Cogeneration Directive. While in most countries the renewables and CHP capacity is small, this does include the majority in terms of the number of RES-E and HECHP plants. The additional administrative burden to add other plants is relatively small in comparison to the initial work on the GO systems.

\section{Possible stakeholder positions}

\subsection{Electricity producers}

The producer's attitude towards tracking schemes depends among others on the attractiveness of the attributes of generation. Producers that possess attractive (i.e. green) attributes would like to gain the full potential additional benefits and might support a fairly transparent tracking system. Producers with less attractive (i.e. carbon intensive or nuclear) attributes would rather like to avoid having a "negative label" attached to their product and might therefore prefer a more opaque tracking mechanism

\footnotetext{
${ }^{12}$ Moreover, the New England Power Pool (NEPOOL) in the US tracks all generation attributes and not only renewable generation. The experience in Australia is still only related to RES-E.
} 
based on statistics. Alternatively, producers could be aiming at transparency to profile themselves as a reliable company.

Producers of supported electricity have an interest in continuity for a large number of years. This mainly means conserving existing benefits from certain support schemes (such as feed-in tariffs). Especially, in the case of exploiting RES-E-based generation units with generation costs far above marketable revenue, a market framework providing them adequately preferential treatment is regarded necessary by RES-E generators. RES-E technologies would also need to be financially attractive for meeting (national) RES-E targets.

Electricity producers wish to avoid unnecessary administrative burdens. A tracking scheme should remain simple enough to prevent considerable efforts for declaration, monitoring, reporting, control and verification.

\subsection{Suppliers}

Suppliers aim at clarity and transparency so that they can create consumer goodwill and trust. In addition, suppliers can have a marketing interest in tracking (green) electricity attributes, because it enables them to create new electricity products. It enables "green" suppliers to enter the market, while it may permit incumbents to implement a strategy aimed at increasing market share by product differentiation. In France, stakeholders mentioned the idea that more information could be useful to devise specific green products, such as electricity coming from a given technology.

In the Netherlands, de-linked tracking of renewable electricity is already implemented. Incumbent suppliers are satisfied with this system giving them the possibility to offer more than one product. They are, however, not certain whether explicit tracking beyond green has any added value to the consumer. Incumbent suppliers believe that consumers can easily see the difference between green and grey electricity, but may not be interested in more differentiation (e.g. between gas, coal or nuclear).

A reason why Dutch incumbent suppliers are currently not in favour of a very advanced tracking system is that they currently compete mostly on price. After the abolishment of discounts on the energy tax, REB, for RES-E, Dutch suppliers have to themselves absorb the (currently rather small) additional costs of green electricity offerings in terms of GO procurement and administration. They do not wish to expand the GO system further nationally in the absence of EU-wide harmonisation of such an advance.

A potential disadvantage of the emergence of an electricity tracking system for suppliers is the additional work related to the handling of electricity portfolios, because they may have to acquire GOs to prove the origin of their electricity. Once consumers have stated their preference to electricity from a certain technology, suppliers must be able to meet consumers' demand for this type of electricity.

\subsection{Traders}

Traders thrive on a liquid market with low transaction costs, where they can find ample trading opportunities. Like suppliers, the traders' attitude towards tracking is mixed. Traders would welcome a liquid de-linked tracking system, preferably with cross-border trading possibilities to maximise arbitrage opportunities.

Traders are generally against contract-tied tracking, because this provides an incentive for reducing the amount of electricity traded on the power exchanges and reduces the liquidity of the market.

\subsection{Consumers}

The emergence of tracking, and specifically the disclosure of generation attributes, basically means that more information is gained about the supplier's portfolio. Due to the increase in information, customers will be able to make a motivated choice among suppliers according to their preferences.

Consumers are in the first place interested in a secure supply of electricity at low cost. The whole process from production to distribution and retail does not matter much to them. Transparency, credibility, reliability (these may require independent verification of tracking results) and low additional costs of "green" generation technology could help the consumer in making an articulate choice for a supplier with a profile of the consumer's liking.

Dutch experience shows that a specific type of electricity generation can be marketed to consumers. It requires, however, that (1) costs for green power are not or only little higher than for regular grey power and (2) it is easy to understand why green power has (environmental) advantages over regular power.

Customers need information to make an articulate choice, but it is doubtful whether this information has to reach a high level of detail. Customers usually consider many components, not the least price and service quality, to make their choice. Yet a certain measure of standardisation in product labels would enable the consumer to make better comparison of competing electricity product offerings.

\subsection{Transmission and distribution system operators (TSOs/ DSOs)}

The TSO/DSOs are responsible for balancing demand and supply. The emergence of a tracking system also leads to new opportunities for the TSOs, namely by becoming the issuing body for GO and manage possible registry for issuing and redeeming GO. For DSOs, it also involves additional services by way of making and forwarding official measurements of the quantity fed into their respective grids on behalf of the GO tracking authority. 


\subsection{Regulators and EU Member State governments}

Governments and regulators have among their first priorities to support a well-functioning, liquid and secure electricity market. They will also consider the integration of tracking with existing policies and they are required to set up reliable tracking systems for disclosure (following EU directives).

In addition, governments will seek to fulfil any obligations regarding greenhouse gas emissions or RES goals. They also have other policy goals, including employment, technology development, security of supply and rural electrification, among others. However, the willingness of EU Member States to implement a certain tracking system will, for instance, depend on the energy system characteristics (imports/export, power trade, etc.) and whether other tracking systems are already in place, the position of market players and their political influence.

The EU Member State governments (with the assistance of regulators) ideally maximise societal welfare, balancing the interests of producers, consumers and other parties at the national level. However, they also have to adhere to regulation coming from the EU level, which puts an additional challenge to those national interests.

The opinion of the Austrian regulator was that the European Commission should specify in more detail the function and use of the GO system. An example is the GO tradable, separated from the electricity, should the GO be the basis for disclosure. Furthermore, there should be GO for balancing energy as well.

\subsection{Exchanges and NGOs/label owners}

Most likely the exchanges will see contract-tied tracking as a threat, as exchanges are liquid trading platforms for electricity. A de-linked tracking system might be more attractive, and might be an opportunity for operators of power exchanges to set up a new trading place.

For NGOs/label owners, most likely the reliability and credibility of the process of transferring the label to end-use customers are important.

\section{Conclusions and lessons learnt}

This paper gives an overview of the key elements of the context for tracking generation attributes in Europe. The analysis of this paper shows that the context matters for tracking generation attributes. On the national level, there are factors, which make the introduction of a tracking system more easy and others, which make it more difficult, and these vary among EU Member States:

- Experiences in tracking of at least part of the market (e.g. for RES-E) can be used as a basis for creating tracking systems.

- Existing regulations on GO and disclosure need to be taken into account, and might need to be adapted in order to create a consistent tracking system.
- The detailed design of the tracking system might depend on features of the electricity market, such as patterns of generation and trade (and the share of imports and exports).

There are additional factors on the European level, which influence the possibilities of introducing a harmonised tracking system across Europe, such as

- The wide variations among EU Member States with respect to details of the implementation of GOs and disclosure.

- The amount of electricity traded on the spot market makes it difficult to link generation to consumption under contract-tied tracking, while this is of no concern under de-linked tracking.

- The increasing cross-border trade of electricity and the establishment of regional electricity markets cause the national electricity systems to become more and more interconnected.

The above-mentioned developments are strong reasons to evolve towards harmonisation of tracking systems in Europe. The key to harmonised tracking is the need for cross-border co-ordination of policies and their implementation. To achieve cross-border recognition of electricity attributes there is a need for setting some common standards.

From the analysis in this paper we can come to the following basic recommendations for the design of a tracking mechanism:

(1) Experiences gained with partial tracking schemes used for feed-in tariffs, quota obligations or fiscal support measures can be useful for implementing more comprehensive tracking mechanisms.

(2) There is great variation among EU Member States in market opening and the role of power exchanges varies. Due to the Electricity Directive, there will be more harmonisation with respect to market opening and power exchanges. Tracking systems need to be flexible enough to be operational under the variable conditions now and in the future.

(3) Explicit tracking via de-linked tracking systems and/or contracts should be prioritised over the use of statistical averages.

(4) Where a default set of attributes is needed, a residual mix should be used instead of uncorrected generation statistics in order to minimise multiple counting.

(5) It should be sufficiently flexible to accommodate policies and markets in the EU.

Further research could focus on the interaction between $\mathrm{CO}_{2}$ emission reduction targets and renewable energy support. This has already been hotly debated in the academic literature. On the link between carbon markets and renewable certificates see, for instance, Boots (2004), 
Del Río et al. (2005) and Unger and Ahlgren (2005). On the stimulation of renewable electricity in the EU see Egenhofer and Jansen (2006), whereas Voogt and Uyterlinde (2006) point out the costs. Stimulation of renewable electricity in the US is done via renewable portfolio standards (Wiser et al., 2005). Also, the introduction of white certificates on energy saving and their relation to GOs could be an important topic for further research.

GO and TREC systems have been implemented for the comprehensive tracking of eligible RES-E in some EU Member States, and experience with these systems - while still limited to a few countries and a few years at this moment - will grow rapidly. Expansion of existing electronic GO schemes to other sources of generation is likely to be relatively easy and to incur quite low additional costs. However, concerns over the introduction of explicit tracking can be expected from some stakeholders who believe that this will influence the electricity market and, in the absence of harmonisation, will cause higher costs to them rather than to their competitors.

De-linked tracking seems to be the best option, because it minimises the impact on the electricity market, while delivering accurate results. GO schemes can be designed in a way that they incur low cost, are reliable and accurate, and minimise the possibility for multiple counting. If wished for, GO can also be used for tracking bilateral electricity contracts by "tagging" them onto the contract. In this way, a registry-based tracking system can leave it to the preferences of market players whether attributes are allocated on a contract-tied or de-linked tracking path.

\section{Acknowledgements}

We are grateful for the European Commission for funding the project "A European Tracking System for Electricity (E-TRACK)" through the IEE programme (Contract No. EIE/04/141/S07.38594). For more details, see the project website http://www.e-track-project.org.

\section{References}

AIB, 2006. Revised certificate activity figures for the period April 2005-March 2006 <www.aib-net.org/portal/page/portal/AIB_HOME/ AIB_MEM/ADMIN/DOCS/STATISTICS/AIB-2006-Statistics-Mar. pdf $>$.

Boardman, B., Palmer, J., Arvidson, A., Buerger, V., Green, J., Lane, K., Lipp, J., Nordstrom, M., Ritter, H., Timpe, C., Urge-Vorsatz, D., 2003. 4CE Final Report, Prepared as part of the ALTENER project 'Consumer Choice and Carbon Consciousness for Electricity (4CE)' 〈www.electricitylabels.com/downloads/4CE_Final_Report.pdf $\rangle$.

Boots, M., 2004. Green certificates and carbon trading in the Netherlands. Energy Policy 31, 43-50.

CRE, CREG, Dte, 2005. Regional market integration between the wholesale electricity markets of Belgium, France and the Netherlands - A roadmap prepared by CRE, CREG and Dte, December 2005 <www.dte.nl/ images $/ 20051223 \% 20 \mathrm{fb} \% 20$ roadmap\%20final_tcm7-82780.pdf $\rangle$.
Egenhofer, C., Jansen, J.C., 2006. A timetable for harmonisation of support schemes for renewable electricity in the EU. European Review of Energy Markets 1 (2), 57-83.

EU, 2001. Communication from the commission to the European parliament and the council, European energy infrastructure, $\operatorname{COM}(2001) 775$ final <www.europa.eu.int/eur-lex/lex/LexUriServ/ site/en/com/2001/com2001_0775en01.pdf $\rangle$.

EU, 2004. Commission Staff Working Document, Technical Annexes to the Report from the Commission on the Implementation of the Gas and Electricity Internal Market <www.europa.eu.int/comm/energy/ electricity/benchmarking/doc/4/sec_2004_1720_en.pdf $\rangle$.

EU, 2005. Power exchange prices 〈www.europa.eu.int/comm/energy/ electricity/links/index_en.htm $>$.

Jansen, J.C., 2003. A green jewel box? Environmental Finance March, 27.

Jansen, J.C., 2005a. Spreading best practice. Environmental Finance May, $18-20$.

Jansen, J.C., 2005b. Transfer and use of generation attributes. North American Windpower June, 36-39.

Kristiansen, K.O., Jørgensen, R., Lauritzen, J., 2005. Energy source disclosure, renewable energy targets and guarantees of origin a multicertificate response to multiple regulatory requirements, Joule AS and Statnett SF < www.statnett.no/Resources/Filer/Dokumenter/pdf/Multicertificate_model_-_final_version.pdf $\rangle$.

Lise, W., Boots, M.G., de Joode, J., ten Donkelaar, M., Timpe, C., 2006a. Existing tracking schemes for electricity generation attributes in Europe. E-TRACK WP1 Report, ECN-C-05-063.

Lise, W., Timpe, C., Boots, M.G., de Joode, J., ten Donkelaar, M., Vrolijk, C., 2006b. Framework conditions for tracking electricity in Europe. E-TRACK WP2 Report, ECN-C-06-014.

OMEL, 2005. Electricity market 2004 〈http://www.omel.es/en/pdfs/ Memoria2004EN.pdf $>$.

Del Río, P., Hernández, F., Gual, M., 2005. The implications of the Kyoto project mechanisms of the deployment of renewable electricity in Europe. Energy Policy 33, 2010-2022.

SEC, 2004. 547: Commission staff working document. The share of renewable energy in the EU. Country profiles. Brussels, 26 May 2004 〈www.europa.eu.int/comm/energy/res/documents/country_profiles/2004_ 0547_sec_country_profiles_en.pdf $\rangle$.

SKM, 2002. Electricity labelling, Requirements for establishing a reliable well functioning system within the EU <www.gpx.nl/pdf/SKM_ 1.pdf $>$.

Unger, T., Ahlgren, E.O., 2005. Impacts of a common green certificate market on electricity and $\mathrm{CO}_{2}$-emission markets in the Nordic countries. Energy Policy 33, 2152-2163.

Uyterlinde, M.A., Jansen, J.C., Van der Linden, N.H., Vrolijk, C., Green, J., Timpe, C., Bürger, V., Rivero, F., Yerro, G.P., 2004. Guarantees of origin and multiple counting of electricity from renewable sources. REGO Phase 3 Report. ECN report ECN-C-04-098 <www.re-go.info/ downloads/multiple_counting.pdf $>$.

Van der Linden, N.H., Bürger, V., Rivero Garcia, F., Green, J., Jansen, J.C., Timpe, C., Uyterlinde, M.A., Vrolijk, C., White, S., Yerro, G.P., 2004. Guarantees of origin as a tool for renewable energy policy formulation. ECN Report ECN-C-04-078 <www.re-go.info/downloads/ policy_interactions.pdf $>$.

Voogt, M.H., Uyterlinde, M.A., 2006. Cost effects of international trade in meeting EU renewable electricity targets. Energy Policy 34, 352-364.

Vrolijk, C., Green, J., Timpe, C., Bürger, V., van der Linden, N.H., Jansen, J.C., Uyterlinde, M.A., Rivero Garcia, F., Yerro, G.P., 2004. Renewable Energy Guarantees of Origin: implementation, interaction and utilisation. Summary of the RE-GO project <www.re-go.info/ downloads/summary.pdf $>$.

Wiser, R., Porter, K., Grace, R., 2005. Evaluating experience with renewable portfolio standards in the United States. Mitigation and Adaptation Strategies for Global Change 10, 237-263. 